\title{
Additive Manufacturing of Anisotropic Sm-Fe-N Nylon Bonded Permanent Magnets
}

\author{
Kinjal Gandha ${ }^{1}$, Mariappan Paranthaman ${ }^{2}$, Brian Sales $^{3}$, Haobo Wang $^{4}$, Adrian Dalagan ${ }^{3}$, \\ Tej Lamichhane ${ }^{3}$, David Parker ${ }^{3}$, and Ikenna Nlebedim ${ }^{1}$ \\ ${ }^{1}$ Ames Laboratory \\ ${ }^{2}$ Oak Ridge National Laboratory \\ ${ }^{3}$ Oak Ridge National Laboratory Materials Science and Technology Division \\ ${ }^{4}$ Oak Ridge National Laboratory Center for Nanophase Materials Sciences
}

September 25, 2021

\begin{abstract}
Fabricating a bonded magnet with a near-net shape in suitable thermoplastic polymer binders is of paramount importance in the development of cost-effective energy technologies. In this work, anisotropic Sm2Fe17N3 (Sm-Fe-N) bonded magnets are additively printed using Sm-Fe-N anisotropic magnetic particles in a polymeric binder polyamide-12 (PA12). The anisotropic bonded permanent magnets are fabricated by Big Area Additive Manufacturing followed by post-aligned in a magnetic field. Optimal post-alignment results in an enhanced remanence of $\sim 0.68 \mathrm{~T}$ in PA12 reflected in a parallel-oriented (aligned) measured direction. The maximum energy product achieved for the additively printed anisotropic bonded magnet of Sm-Fe-N in PA12 polymer is $78.8 \mathrm{KJ} \mathrm{m}-3$. Our results show advanced processing flexibility of additive manufacturing for the development of Sm-Fe-N bonded magnets in polymer media designed for applications with no critical rare earth magnets.
\end{abstract}

\section{Additive Manufacturing of Anisotropic Sm-Fe-N Nylon Bonded Permanent Magnets}

Kinjal Gandha1 , M. Parans Paranthaman ${ }^{2 *}$, Brian C. Sales ${ }^{3}$, Haobo Wang, ${ }^{2,4}$ Adrian Dalagan, ${ }^{2}$ Tej N. Lamichhane, ${ }^{2}$ David S. Parker ${ }^{3}$ and Ikenna C. Nlebedim ${ }^{1}$

${ }^{1}$ Critical Materials Institute, Ames Laboratory, Ames, IA 50011, USA ${ }^{2}$ Chemical Sciences Division, Oak Ridge National Laboratory, Oak Ridge, TN 37831, USA ${ }^{3}$ Materials Science and Technology Division, Oak Ridge National laboratory, Oak Ridge, TN 37831, USA ${ }^{4}$ The Bredesen Center, The University of Tennessee, Knoxville, TN 37996, USA

\begin{abstract}
Fabricating a bonded magnet with a near-net shape in suitable thermoplastic polymer binders is of paramount importance in the development of cost-effective energy technologies. In this work, anisotropic $\mathrm{Sm}_{2} \mathrm{Fe}_{17} \mathrm{~N}_{3}(\mathrm{Sm}-\mathrm{Fe}-\mathrm{N})$ bonded magnets are additively printed using Sm-Fe-N anisotropic magnetic particles in a polymeric binder polyamide-12 (PA12). The anisotropic bonded permanent magnets are fabricated by Big Area Additive Manufacturing followed by post-aligned in a magnetic field. Optimal post-alignment results in an enhanced remanence of $\sim 0.68 \mathrm{~T}$ in PA12 reflected in a parallel-oriented (aligned) measured direction. The maximum energy product achieved for the additively printed anisotropic bonded magnet of Sm-Fe-N in PA12 polymer is $78.8 \mathrm{KJ} \mathrm{m}^{-3}$. Our results show advanced processing flexibility of additive manufacturing for the development of Sm-Fe-N bonded magnets in polymer media designed for applications with no critical rare earth magnets.
\end{abstract}


Keywords: SmFeN Nylon bonded permanent magnets; additive manufacturing or 3D printing; mechanical properties; magnetic properties.

*Correspondence: paranthamanm@ornl.gov

Introduction

High-performance permanent magnets such as Nd-Fe-B with Dy addition are extensively used in electromagnetic devices and motors for hybrid vehicles. ${ }^{[1-4]} \mathrm{Nd}$ and Dy are key critical materials in the manufacturing of Nd-Fe-B magnets that require high energy density and efficiency at high operating temperatures. The criticality of rare earth metals such as Nd, Dy, etc., make them vulnerable to potential supply chain disruption, and the ever-increasing demand for high-performance permanent magnets has stimulated intense research in producing alternatives to $\mathrm{Nd}-\mathrm{Dy}-\mathrm{Fe}-\mathrm{B}$ magnets. $\mathrm{Sm}_{2} \mathrm{Fe}_{17} \mathrm{~N}_{3}(\mathrm{Sm}-\mathrm{Fe}-\mathrm{N})$ compound is known to have a high saturation magnetization, a large anisotropy field, and a high Curie temperature ${ }^{[5]}$ and thereby seems suitable for advanced technological applications. However, $\mathrm{Sm}_{2} \mathrm{Fe}_{17} \mathrm{~N}_{3}$ intermetallic compound prepared by the nitrogenation of $\mathrm{Sm}-\mathrm{Fe}$ alloy powder cannot be applied to the production of $\mathrm{Sm}-\mathrm{Fe}-\mathrm{N}$ bulk magnets using the sintering technique since it is not stable at high temperatures and decomposes into $\alpha-\mathrm{Fe}$ and $\mathrm{Sm}-\mathrm{N}$ phases above $873 \mathrm{~K} .{ }^{[6]}$ Therefore, the attainment of $\mathrm{Sm}-\mathrm{Fe}-\mathrm{N}$ bulk magnet requires powder densification and avoiding thermal decomposition. To overcome this obstacle, various attempts using non-thermal and low-thermal processes have been made to consolidate $\mathrm{Sm}-\mathrm{Fe}-\mathrm{N}$ powders while avoiding the degradation of the magnet properties. For example, $\mathrm{Sm}-\mathrm{Fe}-\mathrm{N}$ bulk magnets are developed using consolidation techniques such as shock compaction ${ }^{[7,8]}$, hot-pressing ${ }^{[9]}$ and compression shearing methods. ${ }^{[10-12]}$

Magnet manufacturing of bonded magnets has greater flexibility over both sintered and hot deformed type magnets. Mainly, two approaches, compression and injection molding have been chosen as benchmark techniques to fabricate rare earth bonded magnets. Although this method enables manufacturing of complex and near net shape geometries, they require specific tooling for each design, increasing the associated costs. In this context, additive manufacturing (AM) emerges as a capable and flexible technology for producing bonded magnets, with the capacity of obtaining customized shapes without the need for molds since computer-aided design (CAD) models are used to construct three-dimensional parts in a layer-by-layer stacking of raw materials. Innovative developments in AM have renewed research interest in the manufacturing of bonded magnets. ${ }^{[13-19]}$ AM offers several processing advantages: it minimizes waste, eliminates tooling needs, and accelerates time to market. From a materials processing perspective, there is additional flexibility to print AM bonded magnets in different polymer media since it imparts better and desired thermal stability for various desired applications. Considering the main challenges and perspectives for bonded magnets manufacturing through AM, anisotropic Sm-Fe-N powder in PA12 polymer matrix bonded magnets are investigated in this study. Microstructural, magnetic properties, and mechanical property of built samples were characterized in detail.

Experimental Procedure

Composite pellets of compounded Sm-Fe-N (Wellmax S3A-14M grade of Sumitomo Metal Mining Co. Ltd.) in nylon PA12 were used for 3D printing via the Big Area Additive Manufacturing (BAAM) process. Details of the BAAM process and post-printing magnetic field alignment have been previously discussed. ${ }^{[14,15,17]}$ The magnetic hysteresis loops of both as-printed and post-printing aligned bonded magnets along the easy axis (parallel) were measured at $300 \mathrm{~K}$ using a Quantum Design SQUID magnetometer. Morphologies of the bonded magnets were examined by scanning electron microscopy (FEI Teneo). X-ray diffraction of asprinted bonded magnets was performed with a Bruker diffractometer using $\mathrm{Cu}-\mathrm{K} \alpha$ radiation. The mechanical properties of the BAAM printed Sm-Fe-N nylon magnets were evaluated on tensile test specimen (SS3 ASTM standard dog bone design) along the deposition direction. Details of the measurements techniques were reported previously. ${ }^{[14,15]}$

Results and Discussion

Microstructure 
Figure 1 shows the image of the as-printed magnet and the scanning electron microscope (SEM) micrograph of the as-printed bonded magnet that reveals the morphology of the anisotropic Sm-Fe-N powder in PA12 matrix. As shown in Fig. 1b, the average particle size of Sm-Fe-N powder is $3 \mu \mathrm{m}$ in a PA12 polymer matrix with no significant voids or cracks. It is known that the particle size and shape can affect the viscosity of the bonded magnets. ${ }^{[19,20]}$ For example, the orientation of the high aspect ratio particles affects the overall viscosity of the system since the particles tend to align along the shear plane. It is reported that the viscosities of non-spherical Nd-Fe-B suspensions are generally higher than the viscosities of spherical Nd-Fe-B suspensions. ${ }^{[20-22]}$ Therefore, the particle shape and size could not only affect the rheology of the binder but also the loading fraction in the polymer thereby altering the magnetic properties and thermal stability of the bonded magnets.

\section{Hosted file}

image1.emf available at https://authorea.com/users/437046/articles/538959-additivemanufacturing-of-anisotropic-sm-fe-n-nylon-bonded-permanent-magnets

Figure 1. (a) As-printed image and (b) SEM micrograph of the as-printed bonded magnets: Sm-Fe-N powder in PA12 matrix.

The structure of the additively printed Sm-Fe-N bonded magnets in PA12 was examined by XRD. Figure 2 shows the XRD pattern of the as-printed bonded magnet. The XRD studies indicate that $\mathrm{Sm}-\mathrm{Fe}-\mathrm{N}$ bonded magnets did not reveal any undesired nitrides such as $\mathrm{SmN}, \alpha-\mathrm{Fe}$ and oxide phase, unlike other 3D metal printing techniques ${ }^{[23,24]}$ but only consisted of the main $\mathrm{Sm}_{2} \mathrm{Fe}_{17} \mathrm{~N}_{3}$ phase. Therefore it can be concluded that the additive printing did not cause any degradation of the main phase of the initial magnetic powder.

\section{Hosted file}

image2.emf available at https://authorea.com/users/437046/articles/538959-additivemanufacturing-of-anisotropic-sm-fe-n-nylon-bonded-permanent-magnets

Figure 2. X-ray diffraction patterns of the as-printed bonded magnets: $\mathrm{Sm}-\mathrm{Fe}-\mathrm{N}$ powder in PA12 matrix.

Magnetic properties

Figure 3 shows the magnetic hysteresis loops of the as-printed and post-aligned Sm-Fe-N PA12 bonded magnets measured parallel to the alignment direction, at different magnetic field strengths. The minimum alignment field to orient the magnetic particles is determined by applying an external magnetic field with varying strengths $(0.5,1.0,1.5,2.0,2.5$, and $3.0 \mathrm{~T})$ during the post-printing alignment process. Printed magnets were heated from 300 to $550 \mathrm{~K}$ with a dwell time of 15 min at $550 \mathrm{~K}$, and then cooled to 300 $\mathrm{K}$ during the post-printing alignment process. After each alignment process, the magnetic hysteresis loops were measured again at $300 \mathrm{~K}$. A significant increase in the remanence and a small decrease in coercivity were observed with increasing magnetic field strength from 0.5 to $3.0 \mathrm{~T}$. The concentration of particles embedded in a polymer matrix affects the magnetic properties of the bonded magnet. The saturation magnetization directly increases with higher loading of magnetic fraction and the effect of the magnetic field during alignment thereby increases the $B_{r}$ and $M_{s}$. Several factors can affect coercivity of the bonded magnets namely the increase in dipole interaction due to high magnetic fraction content, and the variation in the degree of grain alignment leading to plausible cause for the reduction in coercivity. ${ }^{[20,25]}$

Table 1 shows the magnetic properties of the anisotropic bonded magnets as a function of magnetic alignment fields. The as-printed sample has a low remanence, $\mathrm{B}_{\mathrm{r}}=0.35 \mathrm{~T}$, and higher coercivity, $\mathrm{H}_{\mathrm{c}}=557 \mathrm{kA} \mathrm{m}^{-1}$. For the $1.0 \mathrm{~T}$ alignment field, the remanence of the magnet $(0.67 \mathrm{~T})$ is much higher indicating the high degree of grain alignment of the powders. The coercivity at $1 \mathrm{~T}\left(501 \mathrm{kA} \mathrm{m}^{-1}\right)$ is slightly lower but an enhanced $(\mathrm{BH})_{\max }$ of $75.6 \mathrm{KJ} \mathrm{m}^{-3}$ is achieved, compared to the no-field and $0.5 \mathrm{~T}$ alignment field samples. For magnetic field strengths above $1 \mathrm{~T}$, the coercivity remains unchanged at $501 \mathrm{kA} \mathrm{m}^{-1}$ while $\mathrm{B}_{\mathrm{r}}$ and $(\mathrm{BH})_{\max }$ slightly improved to $0.68 \mathrm{~T}$ and $78.8 \mathrm{KJ} \mathrm{m}^{-3}$. For example, increasing the alignment field from $1 \mathrm{~T}$ to $3 \mathrm{~T}$ yielded 
$\sim 1.5 \%$ increase in $\mathrm{B}_{\mathrm{r}}$. However the percentage increase in $(\mathrm{BH})_{\max }$ is higher $(\sim 4.2 \%)$ due to the increased $\mathrm{B}_{\mathrm{r}}$ and resultant improved squareness of the hysteresis loop.

\section{Hosted file}

image3.emf available at https://authorea.com/users/437046/articles/538959-additivemanufacturing-of-anisotropic-sm-fe-n-nylon-bonded-permanent-magnets

Figure 3. M-H loops of the as-printed, and post-aligned Sm-Fe-N PA12 bonded magnets (with varying magnetic field strengths of $0.5,1.0,1.5,2.0,2.5$, and $3.0 \mathrm{~T}$ ) measured parallel to the alignment direction. Samples were heated from 300 to $550 \mathrm{~K}$ with a dwell time of 15 min at $550 \mathrm{~K}$, and then cooling to $300 \mathrm{~K}$ during the post alignment process.

The attainment of remanence values as high as $0.68 \mathrm{~T} \mathrm{kG}$ and coercivity as high as $501.3 \mathrm{kA} \mathrm{m}^{-1}$, with energy products approaching $78.8 \mathrm{KJ} \mathrm{m}^{-3}$, is highly significant in an additively manufactured $\mathrm{Sm}-\mathrm{Fe}-\mathrm{N}$ magnet, considering that one of the constituent magnet powders, the Sumitomo Wellmax $14 \mathrm{M}$, is rated to just $111.4 \mathrm{KJ} \mathrm{m}^{-3}$ with remanence under $0.8 \mathrm{~T}$. Our additively manufactured magnets are achieving over $70 \%$ of rated performance, measured as energy product, and over $80 \%$ of rated remanence.

Table 1. Magnetic properties of BAAM printed Sm-Fe-N PA12 magnets.

\begin{tabular}{llll}
\hline Alignment Field & $\mathrm{H}_{\mathrm{c}}(\mathrm{kA} / \mathrm{m})$ & $\mathrm{B}_{\mathrm{r}}(\mathrm{T})$ & $(\mathrm{BH})_{\max }\left(\mathrm{KJ} / \mathrm{m}^{3}\right)$ \\
\hline No Field & 557 & 0.35 & 20.1 \\
$0.5 \mathrm{~T}$ & 588.8 & 0.485 & 39.5 \\
$1.0 \mathrm{~T}$ & 501.3 & 0.67 & 75.6 \\
$1.5 \mathrm{~T}$ & 501.3 & 0.67 & 76.4 \\
$2.0 \mathrm{~T}$ & 501.3 & 0.673 & 77.2 \\
$2.5 \mathrm{~T}$ & 501.3 & 0.676 & 78.0 \\
$3.0 \mathrm{~T}$ & 501.3 & 0.68 & 78.8 \\
\hline
\end{tabular}

\section{Mechanical properties}

The mechanical properties of the BAAM printed Sm-Fe-N PA12 magnets are a vital property to be determined to obtain its basic information in performance. Figure 4 presents the room temperature tensile stress displacement curves of BAAM printed Sm-Fe-N magnets. Four dog-bone shaped specimens were tested to determine the degree of variability in mechanical properties between samples. Note that the "tails" at the start of the curve in Figure 3 are associated with the test conditions. The nature of the tensile profile of the sample exhibits three major reason before the ultimate breakage as shown in Figure 4. The initial inclined region is a regular extension of composite with stress. The predominant constant stress between $0.5 \%$ to up to $3 \%$ extension in two samples is the rotation of anisotropic particles in the pulling direction with maximum shear stress. The final elastic stage is the inclined straight-line section extracting the ultimate strength and Young's modulus. The major mechanical parameters and average for all the samples is shown in Table 2. The ultimate strength greatly varies between 6 to $12 \mathrm{MPa}$ which we believe are the two limits of isotropic Nd-Fe-B Nylon ${ }^{[15]}$ and anisotropic Nd-Fe-B Nylon ${ }^{[14]}$ BAAM magnets.

\section{Hosted file}

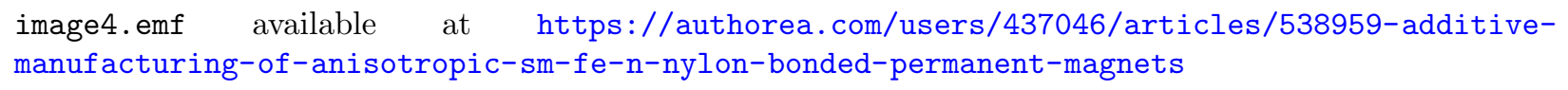

Figure 4. Mechanical properties of the BAAM printed Sm-Fe-N PA12 magnets. Tensile stress displacement curves of the BAAM printed Sm-Fe-N magnets; the inset shows the images of the four samples after tensile testing indicating the location of failure.

Table 2: Tensile parameters for BAAM printed Sm-Fe-N PA12 magnets. 


\begin{tabular}{lllll}
\hline Sample \# & Yield tensile strength $(\mathrm{MPa})$ & Yield tensile strain \% & Ultimate tensile strength $(\mathrm{MPa})$ & Ultimate tensile stra \\
\hline 1 & 10.43866 & 0.95 & 12.47951 & 1.047 \\
2 & 3.723169 & 3.205 & 6.239755 & 3.321 \\
3 & 7.108495 & 0.832 & 9.142448 & 1.196 \\
4 & 3.688695 & 3.977 & 12.33472 & 4.014 \\
Average & 5.660596 & 2.2 & 8.783921 & 2.378 \\
\hline
\end{tabular}

$\mathrm{Sm}_{2} \mathrm{Fe}_{17} \mathrm{~N}_{3}$ has been known for many years, dating back to its original discovery by Coey et al. some 30 years ago ${ }^{[26]}$, as a magnetic material that has not achieved its full potential of energy products rivalling that of $\mathrm{Nd}_{2} \mathrm{Fe}_{14} \mathrm{~B}$, due to its high-temperature stability difficulties impeding sintering. Recent first principles calculations ${ }^{[27]}$ suggest substitutions such as La or Ce may enhance its high-temperature stability while maintaining relevant magnetic properties (in particular, sufficient magnetic anisotropy). Such effects, if experimentally confirmed, would presumably persist to additively manufactured magnets as considered here, and would offer the promise of an alternative family of permanent magnets with performance, for both sintered and bonded magnets, comparable to that of $\mathrm{Nd}_{2} \mathrm{Fe}_{14} \mathrm{~B}$. This would be an important step, both for magnet development as well as resource criticality, given the present underutilization of Sm, which effectively increases the cost and criticality of the more commonly used Nd and Dy.

Conclusion

This paper presents AM fabrication and characterization which includes magnetic properties and mechanical properties of BAAM printed anisotropic Sm-Fe-N based magnets in Nylon (PA12) polymer. Microstructural analysis of AM printed bonded magnet by XRD indicates there is no degradation of Sm-Fe-N main phases after 3D printing. An enhanced remanence of $\sim 0.68 \mathrm{~T}$ and coercivity of $501.3 \mathrm{kA} \mathrm{m}^{-1}$ is achieved in PA12 after optimizing post-alignment. The maximum energy product achieved for additively printed anisotropic bonded magnet of $\mathrm{Sm}-\mathrm{Fe}-\mathrm{N}$ in PA12 polymer is $78.8 \mathrm{KJ} \mathrm{m}^{-3}$. The production of additively printed anisotropic $\mathrm{Sm}-\mathrm{Fe}-\mathrm{N}$ bonded magnets offers the advantage for bonded magnets manufacturing through AM and enables efficient use of rare earth elements thus contributing towards addressing the reduced need of critical materials.

\section{Acknowledgments}

This research was supported by the Critical Materials Institute, an Energy Innovation Hub funded by the U.S. Department of Energy, Office of Energy Efficiency and Renewable Energy, Advanced Manufacturing Office. Work was performed, in part, at Ames Laboratory operated for the U.S. Department of Energy by Iowa State University of Science and Technology under Contract No. DE-AC02-07CH11358. Part of the printing efforts at Oak Ridge National Laboratory was supported by the U.S. Department of Energy, Office of Energy Efficiency and Renewable Energy, Wind Energy Technologies Office Program. Thanks are due to Brian Post and John Lindahl with BAAM printing of magnets.

This manuscript has been authored in part by UT-Battelle, LLC, under contract DE-AC05-00OR22725 with the US Department of Energy (DOE). The US Government retains and the publisher, by accepting the article for publication, acknowledges that the US government retains a nonexclusive, paid-up, irrevocable, worldwide license to publish or reproduce the published form of this manuscript or allow others to do so, for US government purposes. DOE will provide public access to these results of federally sponsored research in accordance with the DOE Public Access Plan (http://energy.gov/downloads/doe-public-access-plan).

\section{CONFLICT OF INTEREST}

The authors declare no potential conflict of interest.

\section{AUTHOR CONTRIBUTIONS}

Kinjal Gandha, Brian C Sales, Haobo Wang, Adrian Dalagan, Tej N. Lamichhane, David S Parker: Conceptualization; formal analysis; methodology; resources; validation; visualization; writing-original draft; 
writing-review and editing. M. Parans Paranthaman, Ikenna C. Nlebedim: Investigation; methodology; supervision; validation; visualization; writing-original draft; writing-review and editing.

References

[1] K. H. J. Buschow, Rep Prog Phys 1991, 54, 1123.

[2] K. H. J. Buschow, F. R. Boer, Physics of magnetism and magnetic materials, Vol. 7, Springer, 2003.

[3] J. M. D. Coey, Magnetism and magnetic materials , Cambridge university press, 2010.

[4] J. M. D. Coey, IEEE Transactions on Magnetics 2011, 47, 4671.

[5] J. M. D. Coey, H. Sun, Journal of Magnetism and Magnetic Materials 1990, 87, L251.

[6] F. Cabral, S. Gama, E. De Morais, N. Sanjurjo, C. Rubeiro, C. Colucci, IEEE Transactions on Magnetics $1996,32,4365$.

[7] M. Leonowicz, W. Kaszuwara, E. Jezierska, D. Januszewski, G. Mendoza, H. A. Davies, J. Paszula, Journal of Applied Physics 1998, 83, 6634.

[8] T. Mashimo, X. Huang, S. Hirosawa, K. Makita, Y. Kato, S. Mitsudo, M. Motokawa, Journal of Magnetism and Magnetic Materials 2000, 210, 109.

[9] K. Otogawa, K. Takagi, T. Asahi, Journal of Alloys and Compounds 2018, 746, 19.

[10] T. Saito, M. Fukui, H. Takeishi, Scripta Materialia 2005, 53, 1117.

[11] T. Saito, H. Sato, M. Fukui, H. Takeishi, Journal of Applied Physics 2006, 99, 08 B509.

[12] T. Saito, H. Sato, H. Takeishi, N. Nakayama, Applied Physics Letters 2006, 89, 162511.

[13] C. Huber, C. Abert, F. Bruckner, M. Groenefeld, S. Schuschnigg, I. Teliban, C. Vogler, G. Wautischer, R. Windl, D. Suess, Scientific Reports 2017, 7, 9419.

[14] K. Gandha, I. C. Nlebedim, V. Kunc, E. Lara-Curzio, R. Fredette, M. P. Paranthaman, Scripta Materialia 2020, 183, 91.

[15] L. Li, A. Tirado, I. C. Nlebedim, O. Rios, B. Post, V. Kunc, R. R. Lowden, E. Lara-Curzio, R. Fredette, J. Ormerod, T. A. Lograsso, M. P. Paranthaman, Sci Rep 2016, 6, 36212.

[16] M. P. Paranthaman, V. Yildirim, T. N. Lamichhane, B. A. Begley, B. K. Post, A. A. Hassen, B. C. Sales, K. Gandha, I. C. Nlebedim, Materials 2020, 13, 3319.

[17] K. Gandha, L. Li, I. C. Nlebedim, B. K. Post, V. Kunc, B. C. Sales, J. Bell, M. P. Paranthaman, Journal of Magnetism and Magnetic Materials 2018, 467, 8.

[18] J. A. B. Engerroff, A. B. Baldissera, M. D. Magalhães, P. H. Lamarão, P. A. P. Wendhausen, C. H. Ahrens, J. M. Mascheroni, Journal of Rare Earths 2019, 37, 1078.

[19] A. Shen, C. P. Bailey, A. W. K. Ma, S. Dardona, Journal of Magnetism and Magnetic Materials 2018, 462, 220.

[20] A. Shen, X. Peng, C. P. Bailey, S. Dardona, A. W. K. Ma, Materials \& Design 2019, 183, 108133.

[21] R. Domingo-Roca, J. C. Jackson, J. F. C. Windmill, Materials \& Design 2018, 153, 120.

[22] W. Xi, W. Liu, R. Hu, Y. Yin, M. Yue, Materials \& Design 2020, 192, 108767.

[23] J. Jaćimović, F. Binda, L. G. Herrmann, F. Greuter, J. Genta, M. Calvo, T. Tomše, R. A. Simon, Advanced Engineering Materials 2017, 19, 1700098.

[24] N. Emminghaus, C. Hoff, J. Hermsdorf, S. Kaierle, Procedia CIRP 2020, 94, 211. 
[25] R. W. Gao, J. C. Zhang, D. H. Zhang, Y. Y. Dai, X. H. Meng, Z. M. Wang, Y. J. Zhang, H. Q. Liu, Journal of Magnetism and Magnetic Materials 1999, 191, 97.

[26] Y. Otani, D. P. F. Hurley, H. Sun, J. M. D. Coey, Journal of Applied Physics 1991, 69, 5584.

[27] T. Pandey, M.-H. Du, D. S. Parker, Physical Review Applied 2018, 9, 034002. 